\title{
PENGARUH PENGGUNAAN POZOLAN ALAM BANJARNEGARA SEBAGAI BAHAN PENGGANTI SEBAGIAN SEMEN KOMPOSIT TERHADAP KUAT TEKAN MORTAR
}

\author{
Dayat Nurhidayat, Erna Septiandini Nira Nasution
}

\begin{abstract}
Abstrak
Penelitian ini bertujuan untuk mengkaji pengaruh penggunaan pesentase pozolan alam Banjarnegara pada lima perlakuan, dengan perlakuan $E$ tanpa pozolan, dan perlakuan $A, B, C$ dan $D$ berturut-turut dengan variasi $0 \%, 5 \%, 10 \%, 15 \%$ dan $20 \%$ dari berat semen komposit, untuk mencapai kuat tekan mortar normal dan pada persentase berapa dicapai kuat tekan maksimum.

Penelitian ini mengggunakan metode ekperimen sesuai SNI. Pengujian bahan agregat halus dan pengujian mutu dilakukan di Laboratorium Penelitian Bahan dan Barang Dinas Perindustrian DKI Jakarta. Untuk campuran 1 semen komposit : 5 pasir. Jumlah sampel masing-masing perlakuan adalah 5 benda uji, jumlah sempel seluruhnya adalah 25 benda uji. Penelitian ini dilakukan pada bulan AprilJuli 2008.

Berdasarkan perlakuan variasi persentase, hasil uji data memenuhi syarat normalitas dan homogenitas serta analisa varians satu arah dan diuji dengan uji t satu rata-rata satu pihak dengan taraf signifikan $(\alpha)=0.01$. Hasil uji kuat tekan rata-rata $E$ sebesar $9.83 \mathrm{MPa}$ dan kuat tekan rata-rata $\mathrm{A}, \mathrm{B}, \mathrm{C}$ dan $\mathrm{D}$ berturutturut sebesar $8.15 \mathrm{MPa}, 10.37 \mathrm{MPa}, 10.03 \mathrm{MPa}$, dan 11.25 MPa. Nilai kuat tekan rata-rata mortar $\mathrm{B}, \mathrm{C}$ dan $\mathrm{D}$ melebihi nilai kuat tekan rata-rata mortar tanpa pozolan. Berdasarkan hasil uji t didapat persentase maksimum pada mortar D dengan kuat tekan rata-rata sebesar $11.25 \mathrm{MPa}$ dengan persentase pozolan sebesar 20\%. Mortar A, B, C dan D masuk kedalam mortar tipe N (SNI-68822002).
\end{abstract}

Kata kunci: pozolan alam Banjarnegara

\section{PENDAHULUAN}

Di negara berkembang seperti Indonesia, pertumbuhan penduduk yang terus meningkat setiap tahunnya berdampak pada kebutuhan papan yang memadai. Untuk itu, guna memenuhi kebutuhan papan masyarakat banyak didirikan bangunan tinggal seperti rumah, hotel, apartemen, pusat perbelanjaan, perkantoran dan fasilitas lainnya. Pembangunan tersebut berdampak terhadap 
perkembangan dunia konstruksi di Indonesia. Salah satu bentuk kemajuan teknologi adalah kemajuan teknologi di bidang bahan bangunan.

Salah satu komponen bangunan adalah mortar. mortar dibuat dari campuran semen, pasir dan air. Mortar berfungsi sebagai konstruksi struktural sebagai spesi pondasi dan dinding, maupun non struktural sebagai pelapis bagian terluar dinding. Karena fungsi mortar sangat penting dalam konstruksi, perlu adanya penelitian bagaimana cara meningkatkan mutu mortar terutama kuat tekan. Salah satu cara yaitu dengan menambahkan pozolan alam kedalam campuran mortar dengan perbandingan tertentu, diharapkan dapat menghasilkan kuat tekan mortar yang optimum dan memberikan keuntungan ekonomis serta mengurangi sebagian emisi $\mathrm{CO}_{2}$ yang dihasilkan dalam proses pembuatan semen.

Bahan dasar pembuat mortar adalah semen yang berfungsi merekatkan butiran-butiran agregat agar terjadi suatu masa yang kompak/padat, selain itu jaga mengisi rongga-rongga diantara butiran agregat. Semen belum bisa digantikan dengan bahan lain, imbasnya kebutuhan produksi semen terus meningkat. Karena semakin berkurangnya persediaan bahan baku penyusun semen dan untuk mengurangi emisi $\mathrm{CO}_{2}$ yang dihasilkan dalam proses pembuatan semen dengan tidak mengurangi kekuatan, maka perlu dilakukan penelitian mengenai semen alternatif dengan harga murah dan berkualitas baik yang dapat digunakan sebagai bahan untuk campuran semen sehingga penggunaan semen bisa dihemat dan dikurangi. Untuk itu dibutuhkan adanya suatu bahan yang mampu menggantikan semen sebagai bahan pengikat dalam suatu campuran mortar.

Untuk mendapatkan semen alternatif yang dibutuhkan perlu diadakan penelitian. Penelitian merupakan syarat yang dapat dipercaya untuk mendapatkan data yang benar. Penelitian merupakan alat bantu ilmu yang praktis untuk diterapkan dalam rangka mempertinggi hasrat hidup bukan sekedar kegiatan ilmiah untuk ilmu pegetahuan. Beberapa penelitian bahan telah berhasil menambah jenis-jenis bahan bangunan yang lebih murah tetapi memenuhi syarat untuk dapat digunakan sebagai bahan bangunan yaitu mudah didapat, murah dan memenuhi syarat bahan bangunan.

Tingginya kandungan silika yang dimiliki semen menjadikan semen belum mampu digantikan dengan senyawa lain dalam pembuatan mortar, namun hal ini tidak diimbangi dengan ketersediaan sumber bahan utama semen tersebut yang semakin hari semakin berkurang.

Pemakaian pozolan alam sebagai bahan pengganti sebagian semen komposit pada pembuatan mortar adalah untuk mendapatkan campuran yang menghasilkan kekuatan mortar yang memenuhi syarat kekuatan yang telah ditentukan. Pozolan yang digunakan berasal dari Banjarnegara, yang berbentuk batuan yang telah mengalami pelapukan (feldspar) warnanya putih kekuning-kuningan dan diprediksi persediaan bisa mencapai sepuluh tahun kedepan. Melimpahnya kandungan pozolan 
alam di Banjarnegara ini merupakan potensi besar , yang sampai saat ini belum dimanfaatkan secara optimal. Sehingga perlu penanganan serius agar potensi itu dapat dikelola secara maksimal dan dapat dimanfaatkan secara efisien sebagai salah satu bahan alternatif untuk substitusi sebagian semen di masa mendatang.

Pemakaian pozolan alam sebagai bahan pengganti sebagian semen portland komposit pada pembuatan mortar adalah untuk mendapatkan campuran yang menghasilkan kekuatan mortar yang memenuhi syarat, sehingga campurannya dapat dipergunakan untuk menyeimbangkan antara kekuatan dan biaya yang dikeluarkan. Selain itu pemanfaatan pozolan alam sebagai pengganti sebagian semen diharapkan sebagai bahan alternatif sehingga dapat mengurangi pencemaran udara akibat gas $\mathrm{CO}_{2}$ yang dihasilkan dari proses produksi semen dan pemanfaatan bahan pozolan alam yang masih banyak tersedia pada daerah yang memiliki potensi bahan pozolan yang belum dimanfaatkan, menanggulangi keterbatasan bahan baku semen yang sekarang ini makin menipis dan diharapkan pula dapat menjadi salah satu alternatif jenis semen yang dapat digunakan masyarakat karena harganya relatif lebih murah.

Untuk itu diadakanlah penelitian tentang "Pengaruh Penggunaan Pozolan Alam Banjarnegara Sebagai Pengganti Sebagian Semen komposit Terhadap Kuat Tekan Mortar". Berdasarkan penelitian relevan yang telah ada sebelumnya, maka penambahan pozolan alam pada semen komposit dilakukan dengan lima variasi prosentase campuran yaitu: $0 \%, 5 \%, 10 \%, 15 \%$ dan $20 \%$ dari berat semen komposit, dengan komposisi campuran 1 semen : 5 pasir, dan faktor air semen 0.65 . Ini dilakukan untuk mengetahui kadar persentase optimum yang bisa didapat agar mencapai kuat tekan mortar yang optimum.

\section{Penelitian Relevan}

1) Menurut Puslitbang Pemukiman Kimpraswil Bandung (1998), campuran optimum untuk mortar normal adalah dengan perbandingan 1 semen : 3 pasir. Untuk perbandingan $1: 4$ sampai $1: 8$ kuat tekan yang dihasilkan akan semakin menurun terhadap kuat tekan Mortar normal pada umur 28 hari. Kuat tekan Mortar pada umur 28 hari dengan campuran dari $1: 3$ sebesar 19,29 Mpa, $1: 4$ sebesar 19, $07 \mathrm{Mpa}, 1: 5$ sebesar 17,08 Mpa, $1: 6$ sebesar 13,19 Mpa, $1: 7$ sebesar 11,95 Mpa dan 1:8 sebesar 9,04 Mpa

2) Persentase campuran yang digunakan oleh Zaenal Majid dalam penelitiannya menggunakan penggantian semen dengan trass alam dengan variasi, $5 \%, 10 \%, 15 \%, 20 \%, 25 \%$ dan $30 \%$ 
didapatkan hasil makin banyak trass makin rendah kuat desaknya dan kuat desak tertinggi dicapai beton dengan persentase trass $15 \%$

3) Berdasarkan perbandingan campuran dapat dilihat pengaruh kadar semen abu terbang ternyata menentukan kuat tekan mortar, untuk semen abu terbang campuran $1: 2$ dengan masa curing 3 hari, kuat tekan paling tinggi sebesar $376 \mathrm{~kg} / \mathrm{cm}^{2}$ pada umur mortar 180 hari dan semen tipe I diperoleh kuat tekan paling tinggi $369 \mathrm{~kg} / \mathrm{cm}^{2}$ juga pada unsur mortar 180 hari

\section{Bahan-Bahan Penyusun Mortar}

Bahan-bahan penyusun mortar terdiri dari bahan pengikat (semen), bahan pengisi (agregat), dan air (pengaduk). Bahan pengikat yang digunakan bersifat hidrolis yaitu semen komposit dan pozolan. Salah satu bahan yang digunakan dalam penelitian ini adalah pozolan alam Banjarnegara. Pozolan adalah bahan yang mengandung silika atau senyawanya dan alumina, yang tidak mempunyai sifat mengikat seperti semen, akan tetapi dalam bentuknya yang halus dan dengan adanya air, senyawa tersebut akan bereaksi secara kimia dengan kalsium hidroksida pada suhu kamar membentuk senyawa yang mempunyai sifat seperti semen

\section{Kuat Tekan Mortar}

Kuat tekan mortar adalah gaya maksimum persatuan luas yang bekerja pada benda uji mortar berbentuk kubus dengan ukuran tertentu serta berumur tertentu

Untuk menghitung nilai kuat tekan pada pengujian ini dapat dihitung dengan rumus

$$
\sigma_{m}=\frac{P_{m a k s}}{A}
$$

Keterangan :

$$
\begin{array}{ll}
\sigma_{\mathrm{m}} & =\text { Kekuatan Tekan Mortar (Mpa) } \\
P_{\text {maks }} & =\text { Gaya tekan maksimum }(\mathrm{N}) \\
\mathrm{A} & =\text { Luas penampang benda uji }\left(\mathrm{mm}^{2}\right)
\end{array}
$$

Kuat tekan mortar normal.

1) Mortar tipe $\mathrm{M}$ adalah mortar yang mempunyai kekuatan $17,2 \mathrm{Mpa}$,

2) Mortar tipe $S$ adalah mortar yang mempunyai kekuatan $12,5 \mathrm{Mpa}$,

3) Mortar tipe $\mathrm{N}$ adalah mortar yang mempunyai kekuatan 5,2 Mpa, 
4) Mortar tipe $\mathrm{O}$ adalah mortar yang mempunyai kekuatan $2,4 \mathrm{Mpa}$,

\section{METODOLOGI PENELITIAN}

Berdasarkan tujuan penelitian diatas, maka metode yang digunakan dalam penelitian ini adalah metode eksperimen di laboratorium, dengan menggunakan benda uji kubus dengan sisi $5 \mathrm{~cm}$. Untuk mengetahui kuat tekan mortar dengan menggunakan pozolan alam Banjarnegara sebagai bahan pengganti sebagian semen komposit pada persentase $0 \%, 5 \%, 10 \%, 15 \%$ dan $20 \%$ dari berat semen komposit pada perbandingan 1 semen komposit : 5 pasir, untuk mencari kuat tekan optimum.

Teknik sampling dilakukan dengan membuat benda uji yang dikelompokkan menjadi lima perlakuan, masing-masing 5 buah benda uji untuk setiap perlakuan. mortar yang menggunakan $5 \%$ pozolan alam diberi tanda $\mathrm{A}$, mortar yang menggunakan $10 \%$ pozolan alam diberi tanda $\mathrm{B}$, mortar yang menggunakan $15 \%$ pozolan alam diberi tanda C, mortar yang menggunakan $20 \%$ pozolan alam diberi tanda $\mathrm{D}$ dan mortar yang menggunakan $0 \%$ pozolan alam diberi tanda $\mathrm{E}$ sebagai kontrol. Pengujian kuat tekan mortar dilakukan saat umur mortar mencapai 28 hari. Sehingga jumlah seluruh sampel yang digunakan pada penelitian ini sebanyak 25 buah ( 5 buah benda uji x 5 perlakuan).

\section{HASIL PENELITIAN dan PEMBAHASAN}

\section{A. Deskripsi Data}

Data yang diambil dari penelitian ini berdasarkan Standar Nasional Indonesia. syarat fisis dari benda uji dan diuji kuat tekan masing-masing mortar untuk setiap perlakuan. Diambil kuat tekan rata-rata mortar untuk setiap perlakuan

1. Hasil Pengujian Agregat Halus/Pasir

Hasil pengujian agregat halus/pasir yang dilakukan pada bahan dasar pembuatan mortar dapat dilihat pada tabel di bawah ini :

Tabel 1. Hasil Pengujian Agregat Halus/Pasir

\begin{tabular}{|l|c|c|c|}
\hline \multicolumn{1}{|c|}{ Jenis Pengujian } & $\begin{array}{c}\text { Rata-rata } \\
\text { Hasil pengujian }\end{array}$ & $\begin{array}{c}\text { Jumlah } \\
\text { Pengujian }\end{array}$ & Standar \\
\hline Kadar lumpur & 1,530 & 3 & SNI 03-1754-1990 \\
\hline Zat Organis & Sama dengan contoh & 2 & SNI 03-1755-1990 \\
\hline
\end{tabular}




\begin{tabular}{|l|c|c|c|}
\hline \multicolumn{1}{|c|}{ Jenis Pengujian } & $\begin{array}{c}\text { Rata-rata } \\
\text { Hasil pengujian }\end{array}$ & $\begin{array}{c}\text { Jumlah } \\
\text { Pengujian }\end{array}$ & Standar \\
\hline $\begin{array}{l}\text { Gradasi agregat } \\
\text { halus }\end{array}$ & 3.328 & 5 & SNI 03-1968-1990 \\
\hline $\begin{array}{l}\text { Berat jenis dan } \\
\text { penyerapan air } \\
\text { - BJ Kering } \\
\text { - BJ (SSD) } \\
\text { - BJ Semu } \\
\text { - Penyerapan Air }\end{array}$ & 2,442 & 3 & SNI 03-1970-1990 \\
\hline Kadar air & 2,456 & & \\
\hline
\end{tabular}

Berdasarkan tabel diatas mengenai hasil uji terhadap bahan penyusun mortar dapat diketahui bahwa bahan tersebut lolos uji Standar Nasional Indonesia (SNI), sehingga dapat digunakan sebagai campuran pada mortar. Dari hasil uji analisa saringan diketahui bahwa pasir yang digunakan termasuk kedalam zona 3.

2. Hasil Pengujian Kuat Tekan Mortar

Tabel 2. Hasil Pengujian Kuat Tekan Mortar $\left(\mathrm{Kg} / \mathrm{cm}^{2}\right)$

\begin{tabular}{|c|c|c|c|c|c|}
\hline \multirow{2}{*}{ No } & \multicolumn{5}{|c|}{ Data sampel kuat tekan mortar $\left(\mathrm{Kg} / \mathrm{cm}^{2}\right)$} \\
\cline { 2 - 6 } & $\begin{array}{c}\text { Pozolan } \\
0 \%\end{array}$ & $\begin{array}{c}\text { Pozolan } \\
5 \%\end{array}$ & $\begin{array}{c}\text { Pozolan } \\
10 \%\end{array}$ & $\begin{array}{c}\text { Pozolan } \\
15 \%\end{array}$ & $\begin{array}{c}\text { Pozolan } \\
20 \%\end{array}$ \\
\hline 1 & 104.30 & 77.64 & 98.04 & 106.59 & 118.01 \\
\hline 2 & 94.90 & 76.92 & 95.05 & 93.87 & 115.73 \\
\hline 3 & 98.79 & 94.44 & 97.25 & 93.04 & 102.78 \\
\hline 4 & 92.92 & 76.92 & 121.57 & 101.96 & 116.48 \\
\hline 5 & 100.59 & & 106.67 & 105.88 & 109.35 \\
\hline R & 98.30 & 81.48 & 103.72 & 100.27 & 112.47 \\
\hline S & 3.83 & 8.64 & 10.92 & 6.45 & 6.11 \\
\hline
\end{tabular}


Tabel 3. Hasil Pengujian Kuat Tekan Mortar (MPa)

\begin{tabular}{|l|l|l|l|l|l|}
\hline \multirow{2}{*}{ No } & \multicolumn{5}{|l|}{ Data sampel kuat tekan mortar (MPa) } \\
\cline { 2 - 6 } & $0 \%$ & $5 \%$ & $10 \%$ & $15 \%$ & $20 \%$ \\
& Pozolan & Pozolan & Pozolan & Pozolan & Pozolan \\
\hline 1 & 9.29 & 7.69 & 9.51 & 9.30 & 10.28 \\
2 & 9.49 & 7.69 & 9.73 & 9.39 & 10.93 \\
3 & 9.88 & 7.76 & 9.80 & 10.19 & 11.57 \\
4 & 10.06 & 9.44 & 10.67 & 10.59 & 11.65 \\
5 & 10.43 & & 12.16 & 10.66 & 11.80 \\
\hline R & 9.83 & 8.15 & 10.37 & 10.03 & 11.25 \\
\hline S & 0.45 & 0.86 & 1.09 & 0.65 & 0.63 \\
\hline
\end{tabular}

Keterangan:

$\mathrm{R}=$ Rata-rata kuat tekan mortar

$S=$ Standar Deviasi

Hasil Pengujian kuat tekan mortar rata-rata setiap perlakuan, dapat dilihat pada grafik dibawah ini:

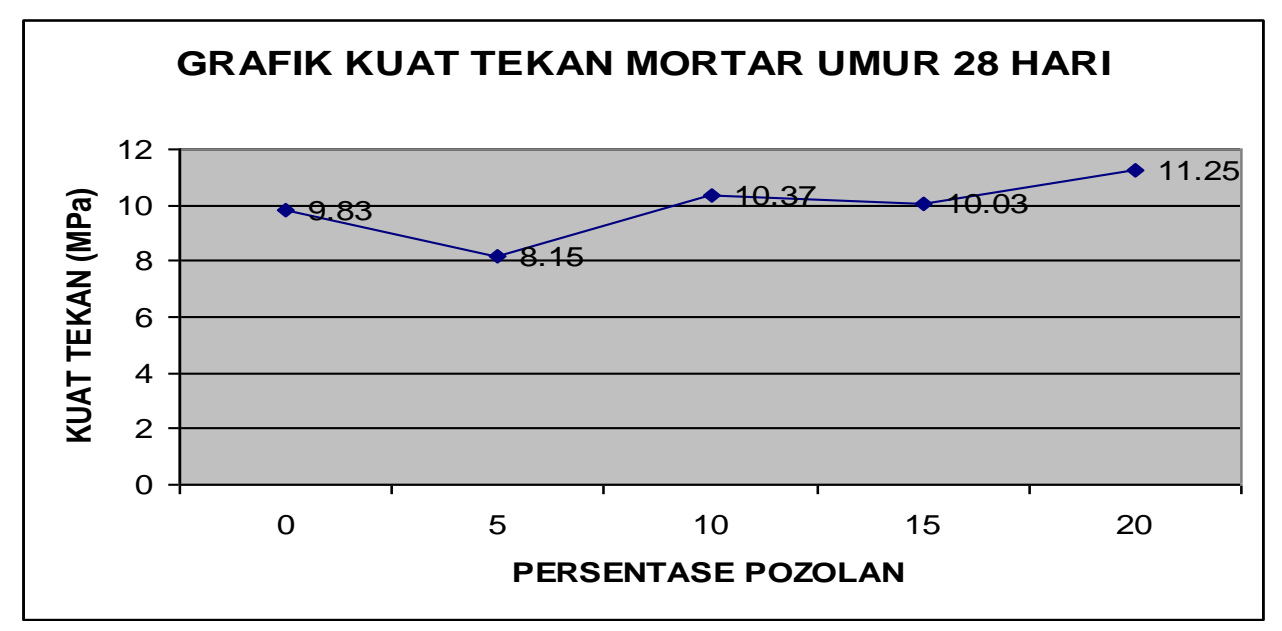

Gambar 1.Grafik Kuat Tekan Mortar Rata-Rata 
3. Hasil Pemeriksaan Kuat Tekan Mortar Rata-Rata Tiap Perlakuan.

Data hasil pengujian kuat tekan rata-rata pada setiap perlakuan yaitu pada persentase $0 \%$ sebesar $9.83 \mathrm{MPa}$, pada persentase 5\% sebesar $8.15 \mathrm{MPa}$, pada persentase 10\% sebesar 10.37 MPa pada persentase $15 \%$ sebesar $10.03 \mathrm{MPa}$, pada persentase $20 \%$ sebesar 11.25 $\mathrm{MPa}$. Pada persentase 5\% kuat tekan rata-ratanya lebih kecil dari kuat tekan rata-rata mortar tanpa pozolan, sedangkan kuat tekan rata-rata mortar dengan menggunakan pozolan alam Banjarnegara pada persentase 10\%,15\%, dan 20\% melebihi kuat tekan rata-rata mortar tanpa pozolan.

\section{Pengujian Persyaratan Analisis data}

1. Uji Normalitas data

Analisa statistik yang digunakan untuk menguji normalitas data adalah uji liliefors, data yang dianalisa adalah data nilai kuat tekan mortar..

a. Uji normalitas data kuat tekan mortar A (5\% Pozolan)

Hasil analisa data yang diperoleh dengan uji liliefors adalah nilai $L O=0,416$ berdasarkan tabel nilai kritis uji liliefors untuk $n$ (sampel) 4 buah dan taraf signifikan $a=0,01$ diperoleh data $L=0,417$ dengan kriteria pengujian apabila $L o<L$ tabel data berdistribusi normal.

b. Uji normalitas data kuat tekan mortar B (10\% Pozolan)

Hasil analisa data yang diperoleh dengan uji liliefors adalah nilai $L O=0,298$ berdasarkan tabel nilai kritis uji liliefors untuk $n$ (sampel) 5 buah dan taraf signifikan $a=0,01$ diperoleh data $L=0,405$ dengan kriteria pengujian apabila $L o<L$ tabel data berdistribusi normal.

c. Uji normalitas data kuat tekan mortar C (15\% Pozolan)

Hasil analisa data yang diperoleh dengan uji liliefors adalah nilai Lo $=0,236$ berdasarkan tabel nilai kritis uji liliefors untuk $\mathrm{n}$ (sampel) 5 buah dan taraf signifikan $\alpha=$ 0,01 diperoleh data $L=0,405$ dengan kriteria pengujian apabila $L o<L$ tabel data berdistribusi normal.

d. Uji normalitas data kuat tekan mortar D (20\% Pozolan)

Hasil analisa data yang diperoleh dengan uji liliefors adalah nilai Lo $=0,198$ berdasarkan tabel nilai kritis uji liliefors untuk $\mathrm{n}$ (sampel) 5 buah dan taraf signifikan $\mathrm{a}=$ 0,01 diperoleh data $L=0,405$ dengan kriteria pengujian apabila $L o<L$ tabel data berdistribusi normal. 
Tabel 4. Hasil Uji Normalitas Data

\begin{tabular}{|c|c|c|c|}
\hline Mortar & LT $_{T}$ & Lo & Kesimpulan \\
\hline A & 0,417 & 0,416 & Normal \\
B & 0,405 & 0,298 & Normal \\
C & 0,405 & 0,236 & Normal \\
D & 0,405 & 0,198 & Normal \\
\hline
\end{tabular}

2. Uji Homogenitas Data

Analisa statistik yang digunakan untuk menguji homogenitas data yaitu dengan uji bartlett, data yang dianalisa untuk uji bartlet yaitu kuat tekan mortar. Hasil pengujian homogenitas dari data mutu kuat tekan Mortar dengan perlakuan Pozolan 5\%, 10\%, 15\% dan $20 \%$ menghasilkan $X^{2}$ Hitung pada taraf nyata signifikan $(a)=0,01$ sehingga diperoleh dari daftar chi-kuadrat $X^{2}$ Tabel, dengan kriteria pengujian $X^{2}$ Hitung $<X^{2}$ Tabel maka dapat disimpulkan varians dari 4 kelompok adalah homogen.

Berikut ini adalah rangkuman uji homogenitas data mutu kuat tekan mortar Tabel 5. Hasil Uji Homogenitas Mutu Kuat Tekan Mortar

\begin{tabular}{|l|l|l|l|l|l|}
\hline $\begin{array}{l}\text { S2 } \\
\text { Gabungan }\end{array}$ & Log S2 & B & $X^{2}$ Hitung & $X^{2}$ Tabel & Hasil \\
\hline 0.68 & -0.167 & -2.505 & 1.53 & 11,3 & $\begin{array}{l}X^{2} \text { Hitung }<X^{2} \text { Tabel } \\
\text { Data Homogen }\end{array}$ \\
\hline
\end{tabular}

Keterangan :

$S^{2}$ gabungan = Varians gabungan dari kelompok $A, B, C$ dan $D$

$\mathrm{B}=\quad=$ Harga besarab diuji kuadrat

$\mathrm{X}^{2} \quad=$ Chi-kuadrat 


\section{B. Pengujian Hipotesis}

1. Hipotesis petama

Pengujian hipotesis kuat tekan mortar menggunakan Pozolan persentase $5 \%, 10 \%$, $15 \%$, dan $20 \%$, hipotesis nol $(\mathrm{Ho})$ sebagai berikut: tidak terdapat pengaruh penggunaan pozolan alam Banjarnegara sebagai bahan pengganti sebagian semen dengan persentase $0 \%, 5 \%, 10 \%, 15 \%$ dan $20 \%$ dari berat semen komposit. Dengan menggunakan uji analisa varians (ANAVA) satu arah dengan taraf signifikan $(\alpha)=0,01$ dengan $F_{\text {hitung }}=10.71$ dan $F_{\text {tabel }}$ $=5.42$. Jadi $F_{\text {hitung }}<F_{\text {tabel, }}$ maka Ho ditolak.

Hasil penelitian adalah terdapat pengaruh penggunaan pozolan alam Banjarnegara sebagai bahan pengganti sebagian semen komposit dengan persentase 5\%,10\%,15\% dan $20 \%$ dari berat semen komposit.

Tabel 6. Rangkuman hasil uji analisis varians (ANAVA) dapat dilihat pada tabel di bawah ini. Hasil Uji Analisis Varians (ANAVA) Kuat Tekan

\begin{tabular}{|l|l|l|l|l|l|}
\hline Sumber Varians & DK & JK & KT & FHitung & F Tabel \\
\hline Rata-rata & 1 & 1916.23 & 1916.23 & & \\
Antar kelompok & 3 & 22.18 & 7.39 & & \\
Dalam kelompok & 15 & 10.31 & 0.69 & 10.71 & 5.42 \\
& & & & & \\
\hline Total & 19 & - & - & - & - \\
\hline
\end{tabular}
Keterangan :
Dk = Derajat Kebebasan
$\mathrm{JK}=$ Jumlah Kuadrat
$\mathrm{KT}=$ Kuadrat Tengah

2. Hipotesis kedua

Hasil Perhitungan menggunakan uji t atau uji kesamaan satu rata-rata uji satu pihak. 
a. Uji t nilai rata-rata kuat tekan mortar mengunakan $5 \%$ pozolan

Hasil analisa data yang diperoleh dari daftar distribusi t dengan $\mathrm{dk}=3$ dan taraf nyata $\mathrm{a}=$ 0,01 diperoleh data $T_{\text {tabel }}=0,454$ dan $T_{\text {hitung }}=-6.14$, sehingga $T_{\text {hitung }}<T_{\text {tabel }}$ maka Ho diterima. Kesimpulanya: Rata-rata kuat tekan mortar yang menggunakan 5\% pozolan sama dengan nilai kuat tekan mortar normal (tanpa pozolan).

b. Uji t nilai rata-rata kuat tekan mortar mengunakan $10 \%$ pozolan

Hasil analisa data yang diperoleh dari daftar distribusi t dengan $\mathrm{dk}=4$ dan taraf nyata $\alpha=$ 0,01 diperoleh $t$ tabel $=3.75$ dan $T_{\text {hitung }}=1.55$, sehingga $t_{\text {hitung }}<t$ tabel, $H_{0}$ diterima . Kesimpulannya: rata-rata kuat tekan mortar yang menggunakan $5 \%$ pozolan sama dengan nilai kuat tekan mortar normal (tanpa pozolan).

c. Uji t nilai rata-rata kuat tekan mortar mengunakan $15 \%$ pozolan Hasil analisa data yang diperoleh dari daftar distribusi t dengan $\mathrm{dk}=4$ dan taraf nyata $\alpha=$ 0,01 diperoleh $t$ tabel $=3.75$ dan $T_{\text {hitung }}=0.93$, sehingga $t_{\text {hitung }}<t$ tabel, $H_{0}$ diterima . Kesimpulannya: rata-rata kuat tekan mortar yang menggunakan $5 \%$ pozolan sama dengan nilai kuat tekan mortar normal (tanpa pozolan).

d. Uji t nilai rata-rata kuat tekan mortar mengunakan $20 \%$ pozolan

Hasil analisa data yang diperoleh Dari daftar distribusi t dengan $\mathrm{dk}=4$ dan taraf nyata $\alpha=$ 0,01 diperoleh $t_{\text {tabel }}=3.75$ dan $\mathrm{T}_{\text {hitung }}=7.06$, sehingga $\mathrm{t}_{\text {hitung }}>\mathrm{t}$ tabel, $\mathrm{H}_{0}$ ditolak . Kesimpulannya: rata-rata kuat tekan mortar yang menggunakan $20 \%$ pozolan kuat tekannya lebih besar dari mortar normal.(tanpa pozolan).

Tabel 7. Hasil Uji t

\begin{tabular}{|c|c|c|c|c|c|c|}
\hline $\begin{array}{c}\text { Perbandingan } \\
\text { campuran }\end{array}$ & $\begin{array}{c}\text { Kuat } \\
\text { tekan(Mpa) }\end{array}$ & $\begin{array}{c}\mathrm{T} \\
\text { hitung }\end{array}$ & $\mathrm{dk}$ & $a$ & $\begin{array}{c}\mathrm{t} \\
\text { tabel }\end{array}$ & kesimpulan \\
\hline $\begin{array}{c}\text { Mortar } 1: 5 \\
\text { (5\% Pozolan) }\end{array}$ & 8.15 & -6.14 & 3 & 0.01 & 4.54 & $\begin{array}{l}\mathrm{T}_{\text {hitung }}<\mathrm{t}_{\text {tabel }} \\
\text { (Ho diterima) }\end{array}$ \\
\hline $\begin{array}{c}\text { Perbandingan } \\
\text { campuran }\end{array}$ & $\begin{array}{c}\text { Kuat } \\
\text { tekan(Mpa) }\end{array}$ & $\begin{array}{c}\mathrm{T} \\
\text { hitung }\end{array}$ & $\mathrm{dk}$ & $a$ & $\begin{array}{c}\mathrm{t} \\
\text { tabel }\end{array}$ & kesimpulan \\
\hline $\begin{array}{l}\text { Mortar } 1: 5 \\
\text { (10\% Pozolan) }\end{array}$ & 10.37 & 1.55 & 4 & 0.01 & 3.75 & $\begin{array}{l}\mathrm{T}_{\text {hitung }}<\mathrm{t}_{\text {tabel }} \\
\text { (Ho diterima) }\end{array}$ \\
\hline $\begin{array}{l}\text { Mortar } 1: 5 \\
\text { (15\% Pozolan) }\end{array}$ & 10.03 & & & & & $\begin{array}{l}\mathrm{T}_{\text {hitung }}<\mathrm{t}_{\text {tabel }} \\
\text { (Ho diterima) }\end{array}$ \\
\hline
\end{tabular}




\begin{tabular}{|l|l|c|c|c|c|c|}
\hline $\begin{array}{c}\text { Perbandingan } \\
\text { campuran }\end{array}$ & $\begin{array}{c}\text { Kuat } \\
\text { tekan(Mpa) }\end{array}$ & $\begin{array}{c}\mathrm{T} \\
\text { hitung }\end{array}$ & $\mathrm{dk}$ & $\mathrm{a}$ & $\begin{array}{c}\mathrm{t} \\
\text { tabel }\end{array}$ & kesimpulan \\
\hline $\begin{array}{l}\text { Mortar } 1: 5 \\
(20 \% \text { Pozolan })\end{array}$ & 11.25 & & & & & $\begin{array}{c}\mathrm{T}_{\text {hitung }}>\mathrm{t}_{\text {tabel }} \\
\text { (Ho ditolak })\end{array}$ \\
\hline
\end{tabular}

Dari perhitungan uji t menunjukan bahwa mortar yang menggunakan persentase $5 \%, 10 \%$, dan $15 \%$ nilai kuat tekannya sama dengan mortar normal (tanpa pozolan). Nilai maksimum kuat tekan mortar dicapai pada mortar yang menggunakan persentase pozolan $20 \%$.

\section{Pembahasan Hasil Penelitian}

Berdasarkan hasil penelitian mortar yang menggunakan Pozolan sebagai pengganti berat semen persentase $0 \%, 5 \%, 10 \%, 15 \%$ dan $20 \%$ berpengaruh pada nilai kuat tekan.

Dilihat dari kuat tekan rata-rata mortar persentase $0 \%$ (mortar normal) menghasilkan nilai rata-rata kuat tekan $9.83 \mathrm{MPa}$ masuk kedalam jenis mortar tipe $\mathrm{N}$, persentase $5 \%$ menghasilkan nilai kuat tekan rata-rata $8.15 \mathrm{MPa}$ masuk kedalam jenis mortar tipe $\mathrm{N}$, persentase $10 \%$ menghasilkan nilai kuat tekan rata-rata 10.37 MPa masuk kedalam jenis mortar tipe $\mathrm{N}$, persentase 15\% menghasilkan nilai kuat tekan rata-rata $10.03 \mathrm{MPa}$ masuk kedalam jenis mortar tipe $\mathrm{N}$, dan persentase $20 \%$ menghasilkan nilai kuat tekan rata-rata $11.25 \mathrm{MPa}$ masuk kedalam jenis mortar tipe N.

Dari hasil statistik menunjukan bahwa kuat tekan maksimum penggunakan variasi persentase pozolan alam Banjarnegara sebagai bahan pengganti sebagian semen komposit dicapai pada persentase $20 \%$ pozolan.

\section{Keterbatasan Penelitian}

Penelitian ini mempunyai beberapa kelemahan diantaranya:

1. Penelitian ini tidak memperhitungkan pengaruh biaya antara mortar yang menggunakan bahan standar dengan mortar yang menggunakan pozolan.

2. Dalam penelitian ini, jumlah benda uji mortar yang diperiksa hanya diambil jumlah minimum benda uji mortar sebanyak 5 buah

3. Dalam proses pengujian dan analisa hasil pengujian, keterbatasan sumber bacaan dan pengetahuan juga ikut mempengaruhi kesimpulan penelitian yang mungkin kurang tepat.

4. Penguji tidak menguji kuat tekan mortar dengan persentase pozolan lebih dari $20 \%$ dari berat semen.

5. Peneliti hanya menguji kuat tekan mortar dengan perbandingan $1: 5$. 


\section{KESIMPULAN, IMPLIKASI DAN SARAN}

\section{A. Kesimpulan}

Bedasarkan hasil penelitian terhadap mortar maka dapat disimpulkan sebagai berikut:

1) Terdapat pengaruh penggunaan pozolan alam Banjarnegara sebagai bahan pengganti sebagian semen komposit pada persentase 0\%,5\%,10\%,15\% dan 20\% dari berat semen komposit terhadap kuat tekan mortar

2) Nilai maksimum kuat tekan mortar menggunakan pozolan alam Banjarnegara dengan persentase $0 \%, 5 \%, 10 \%, 15 \%$, dan $20 \%$ terdapat pada persentase $20 \%$ sebesar 11.25 $\mathrm{MPa}$.(masuk kedalam mortar tipe $\mathrm{N}$ ).

\section{B. Implikasi}

1) Hasil penelitian ini menunjukan bahwa nilai rata-rata kuat tekan mortar menggunakan pozolan alam Banjarnegara sebagai pengganti sebagian semen komposit dengan persentase $10 \%$, $15 \%$, dan $20 \%$, melebihi kuat tekan mortar normal.

2) Penelitian ini memberikan informasi kepada produsen semen bahwa pozolan alam Banjarnegara merupakan bahan alternatif pengganti sebagian semen.

3) Kuat tekan mortar yang menggunakan pozolan alam dapat digunakan untuk pasangan pondasi, dinding, dinding pemikul beban, manhole, sumur, jalan setapak. (masuk kedalan mortar tipe N).

4) Mortar yang menggunakan pozolan alam lebih mudah dikerjakan sehingga dapat digunakan untuk pasangan yang membutuhkan kemudahan pekerjaan.

\section{Saran}

1) Perlu diadakan penelitian lebih lanjut mengenai penggunaan pozolan Banjarnegara sebagai pengganti sebagian semen pada pembuatan mortar dengan persentase lebih dari $20 \%$, untuk mengetahui kuat tekan maksimum yang dihasilkan selanjutnya.

2) Jenis semen yang digunakan pada penelitian ini adalah semen komposit, maka perlu dipertimbangkan untuk penelitian menggunakan semen jenis lainnya. 


\section{DAFTAR PUSTAKA}

Dipohusodo, Istimawan. 1999. Struktur Beton Bertulang. Gramedia Pustaka, Jakarta.

Majid, Zaenal. 2001. Jurnal Teknik Sipil: Kajian Kuat Desak Beton dengan Menggunakan Trass Alam sebagai Substitusi Semen. Semesta Teknika. Vol.4 No.1.

Muhardi, Iskandar Romey Sitompul, dan Rinaldo, 2004. Jurnal Teknik Sipil: Tinjauan kuat tekan mortar terhadap penambahan abu sawit, Vol, 5 No.1. h.1-81.

Nabar, Darmansyah. 1997. Teknika: Kuat Tekan Mortar Semen Abu Terbang. Iptek, Edisi 8.h.2-12.

Nugraha, Paul. 2007. Teknologi Beton dari Material, Pembuatan ke Beton Kinerja Tinggi. Andi, Yogyakarta.

SNI 03-2113-2000. Bata Trass Kapur Untuk Pasangan Dinding Badan Standardisasi Nasional. Jakarta.

SNI 03-6863-2002. Metode Pengambilan Contoh dan Pengujian Abu Terbang atau Pozolan Alam Sebagai Mineral Pencampur dalam Beton Semen Portland. Badan Standardisasi Nasional. Jakarta.

SNI 03-0349-1989. Bata Beton Untuk Pasangan Dinding. Badan Standardisasi Nasional. Jakarta.

SNI 03-3430-1994. Tata Cara Perencanaan Dinding Struktur Pasangan Blok Beton Berongga Bertulang Untuk Bangunan Rumah dan Gedung. Badan Standardisasi Nasional. Jakarta.

SNI 15-0203-2004. Semen Portland Pozolan. Badan Standardisasi Nasional. Jakarta.

SNI 15-7064-2004. Semen Portland Komposit. Badan Standardisasi Nasional. Jakarta.

SNI 03-6825-2002. Metode Pengujian Kuat Tekan Mortar Semen Portland Untuk Pekerjaan Teknik SipilBadan Standardisasi Nasional. Jakarta.

SNI 03-1755-1990, Pemeriksaan kandungan organik dalam agregat halus, Badan Standarisasi Nasional. Jakarta.

SNI 03-1754-1990, Pemeriksaan kandungan lumpur dalam agregat halus, Badan Standarisasi nasional. Jakarta.

SNI 03-1968-1990, Pemeriksaan analisa saringan agregat halus dan kasar. Badan Standarisasi Nasional, Jakarta.

SNI 03-1970- 1990, Metode pengujian berat jenis dan penyerapan air agregat halus. Badan standarisasi Nasional. Jakarta.

SNI 03-6882-2002, Spesifikasi Mortar untuk Pekerjaan Pasangan, Badan Standarisasi Nasional. Jakarta. 
ISSN: $1907-4360$

Sudjana. 1992. Metoda Statistika. Tarsito, Bandung.

Supribadi, IK. 1986. Ilmu Bangunan Gedung Seri Bangunan Sipil A. Armico, Bandung. 